\title{
ANALYSIS OF THE TEMPERATURE DISTRIBUTION OF THE COWS BEARING AREA
}

Dainius RAMUKEVIČIUS, Institute of Hydraulic Engineering, Faculty of Water and Land Management, Vytautas Magnus University, K. Donelaičio g. 58, LT-44248 Kaunas, Lithuania, dainius.ramukevicius@ vdu.lt (corresponding author)

Raimondas ŠADZEVIČIUS, Institute of Hydraulic Engineering, Faculty of Water and Land Management, Vytautas Magnus University. K. Donelaičio g. 58, LT-44248 Kaunas, Lithuanian, raimondas.sadzevicius@ vdu.lt

Rytis SKOMINAS, Institute of Hydraulic Engineering, Faculty of Water and Land Management, Vytautas Magnus University, K. Donelaičio g. 58, LT-44248 Kaunas, Lithuania, rytis.skominas@ vdu.lt

Vincas GURSKIS, Institute of Hydraulic Engineering, Faculty of Water and Land Management, Vytautas Magnus University, K. Donelaičio g. 58, LT-44248 Kaunas, Lithuania, vincas.gurskis@ vdu.lt

Today, economic conditions in the market encourage farmers to look for ways to produce quality produce at a low cost without polluting the environment. This leads to the search for new technologies that make it possible to strike a balance between criteria such as animal welfare, environmental protection and the cost of production. The research carried out reveals a new approach to housing conditions, constructional and technological solutions.

Cowshed ground and the surrounding soil temperature fluctuations have a seasonal nature, as the Lithuanian climate is characterized by temperature change in individual seasons. The cowshed experimental studies show that a significant influence on the ground soil temperature field has the animal radiant heat that transmits not only in the air but also on the ground soil through the floor. The highest temperature of the analyzed soil during the cold season is under the floor of the bearing housing. The temperature relationship of the floor of the bearing housing and the ground soil is especially evident in the coldest winter period. The cowshed floor and surrounding soil temperature measurements showed that the soil temperature field is in a constant dynamic state. The heat transfer, occurring between the outside of the building and the soil under the building as well as at the floor installed over them, is influenced by the external temperature regime.

Keywords: cowshed, cows, temperature.

\section{INTRODUCTION}

Today, new technologies are reverting to more natural housing conditions for cattle, which promotes animal health. Trends in cattle keeping technology and cowshed development are characterized by research-based and internationally regulated provisions: reducing production costs, reducing environmental pollution, and improving animal welfare. The provisions listed are not only the basis for competitive farming but are also the result of international agreements and conventions.

Optimal microclimatic conditions are essential for increasing livestock profitability as well as good feed intake, reducing livestock fall, protecting livestock health, and maximizing productivity. The animal's body can adapt to the changed microclimate, but only to a certain extent (Bagath et al,. 2019). Physiological balance is maintained as long as external stimuli are not stronger than the body can lift. Very strong and unusual factors weaken the body, cause disease, weaken livestock, and degrade the quality of produce.

The evaluation of the housing methods of cows shows that the trade-off between the criteria "animal welfare environmental protection - production cost" is best found in boxing stables, which are considered as "animal welfare benchmark". Such cowsheds are mostly built on farms being modernized in Lithuania. Cowsheds are equipped with deep (richly crawled straw) or shallow (rubber mats or often only concreted and not laid on concrete, i.e. cows lying on concrete) boxes. For further research we have chosen these cowsheds because the main problems with the implementation of cow keeping technologies in this type of cowshed are revealed in adverse climatic conditions (average daily outdoor temperature below $-10^{\circ} \mathrm{C}$ and above $+25^{\circ} \mathrm{C}$ ). If bearing floors are not properly installed in this type of cowshed, the cows will lie down and rest for only 8-9 hours per day. As a result, their productivity is reduced by more than $10 \%$. Flooring is one of the most important components of animal housing as far as animal health and welfare are concerned. Due to poorly equipped bearings floor, in winter too much heat from the animal is released through the floor and the thermoregulatory mechanism of the animal is impaired, his/her well-being deteriorated and productivity is reduced. As a result, poor microclimate results in disruption of the animal's thermoregulatory mechanism increased feed costs and reduced cow productivity by as much as 10-13\% (Hautala et, al,. 2001). These problems are present in many newly built cowsheds in Lithuania, as farmers have not yet mastered the new cow keeping technologies.

Copyright (C) 2019 The Authors. Published by Vytautas Magnus University. This is an open-access article distributed under the terms of the Creative Commons Attribution License (CC BY 4.0), which permits unrestricted use, distribution, and reproduction in any medium, provided the original author and source are credited. 
One of the basic conditions for an animal's well-being is its body's stable temperature. Such a state is only possible with the equilibrium of the heat produced by the animal body and released into the environment. The thermal equilibrium of an animal's body is determined by environmental conditions and thermoregulation of its body. Therefore, as the air temperature in the cowshed changes, the intensity of the energy exchange between the animal and its surrounding environment increases. The animal's body emits heat through radiation, convection, conduction and evaporation of moisture (Figure 1) (Sjostrom, et. al., 2019). All these processes go hand in hand, complement each other and create a sense of thermal comfort in the body. It is difficult to evaluate which process and what exact part it is, as it is determined by many factors: body temperature, intensity of movement, emotional state, coat density, thickness, color, ambient temperature, humidity, etc. Changes in the temperature of an animal's body and its individual organs depend on the heat produced in the body and the energy exchange with the environment. The animal's body temperature is maintained by complex physiological mechanisms that regulate heat production and release. Literature analysis suggests that barn air temperatures can vary within wide limits, affecting cow health and productivity (Sallvik, 1998).

The animal's body wastes energy on physiological functions, which is determined by the total amount of heat produced per day (DeShazer et. al., 2009). The total heat content is 50-75\% of the total energy from the feed. Most of this thermal energy is consumed by animals to maintain a constant body temperature $\left(37.0-39.0^{\circ} \mathrm{C}\right)$. The constant temperature of the animal's body ensures its normal functioning. However, this process can be impaired if the animal is lying on the floor with poor thermal insulation (Liam et. al., 2017.)

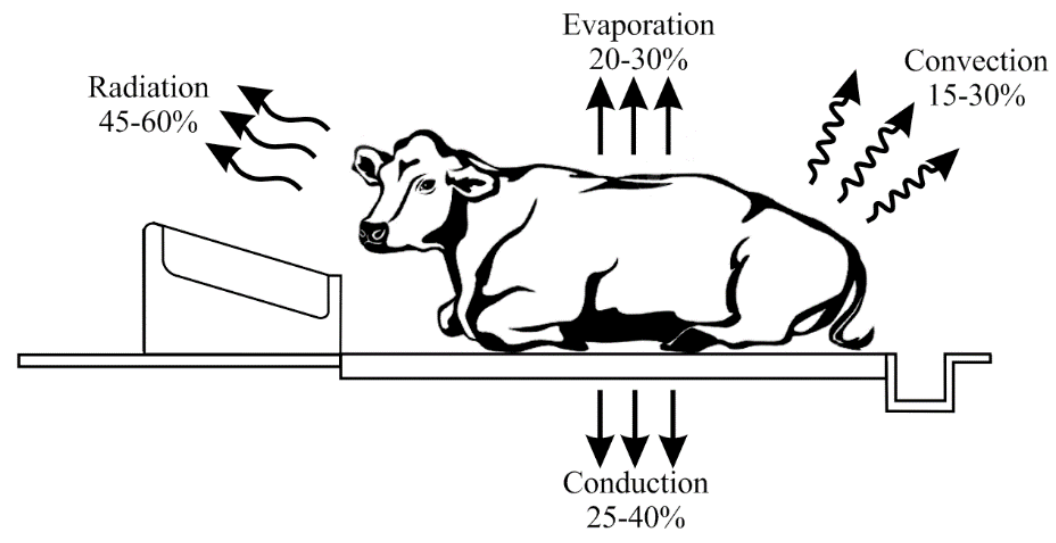

Figure. 1. Thermal energy exchange between animal and the outside

In order to protect livestock from the harmful effects of low temperatures in the bearing area, it is essential to consider the environmental factors that influence the heat exchange through the floor. One such factor is the soil at the base of the building and its surroundings. Since livestock building floors are usually laid on the ground and have no direct contact with the outside, the heat flow through the floor depends not only on the thermal properties of the floor but also on the temperature regime of the ground at the base of the building, because ground, like any building material, are subject to heat exchange patterns. It is also necessary to assess the influence of the temperature of the surrounding ground on the temperature of the building-ground soils, which is directly influenced by the meteorological conditions. In order to decide on the microclimatic conditions in Lithuanian cowsheds, it is first necessary to find out the real situation. To this end, the temperature regime of cowshed-based soils was investigated.

\section{WORK METHODOLOGY}

A cowshed was chosen to determine the soil temperature regime in a cow environment. Research period 2014-2015 years. The total duration of the studies was 225 days.

Cowshed length $-66.6 \mathrm{~m}$, width $-12.5 \mathrm{~m}$, room height $-2.4 \mathrm{~m}$. Cowshed construction: foundation - concrete tape, thickness $-40 \mathrm{~cm}$, foundation depth $-1.1 \mathrm{~m}$, exterior walls - continuous solid brick masonry, thickness $-51 \mathrm{~cm}$. A part of the plan of the cowshed building is shown in Figure 2. The bearing area for one cow is $2.88 \mathrm{~m}^{2}$.

The outdoor air temperature for testing was used using the Kaunas district meteorological station (Kaunas district) observation data. Selecting the soil temperature measuring place in the object, the configuration of the building, animal standing and lying areas are taken into account and the likely impact of external factors is being evaluated. When determining the influence of ground soil temperature regime on the floor surface temperature it is essential to evaluate the foundation. For this reason, boreholes were arranged as close as possible to the foundation both from its internal and external sides, because in order to determine the optimal impact of the building ground and its soil area on floor surface temperature the soil temperature near the building must be determined. 6 soil temperature measurement locations were selected in the study object (Figure 2, I-VI boreholes). The indoor floor surface temperature was measured in the transverse direction of the building. 3 boreholes were drilled for the research of the cowshed soil temperature variation: in the middle of the cowshed, in cows standing place and cows feeding trail - at a distance of $0.6 \mathrm{~m}$ from the outer wall. Also, 3 boreholes have been drilled outside the building at distances of $0.6 \mathrm{~m}, 2.0 \mathrm{~m}$ and $5.0 \mathrm{~m}$ from the outer wall. The 
soil temperature variation capture sensors were arranged in each borehole in vertical direction at distances of $0.25 \mathrm{~m}, 0.5$ $\mathrm{m}, 1.0 \mathrm{~m}, 2.0 \mathrm{~m}$ and $3.0 \mathrm{~m}$ from the ground surface. The measurements were carried out 1-2 times a week.
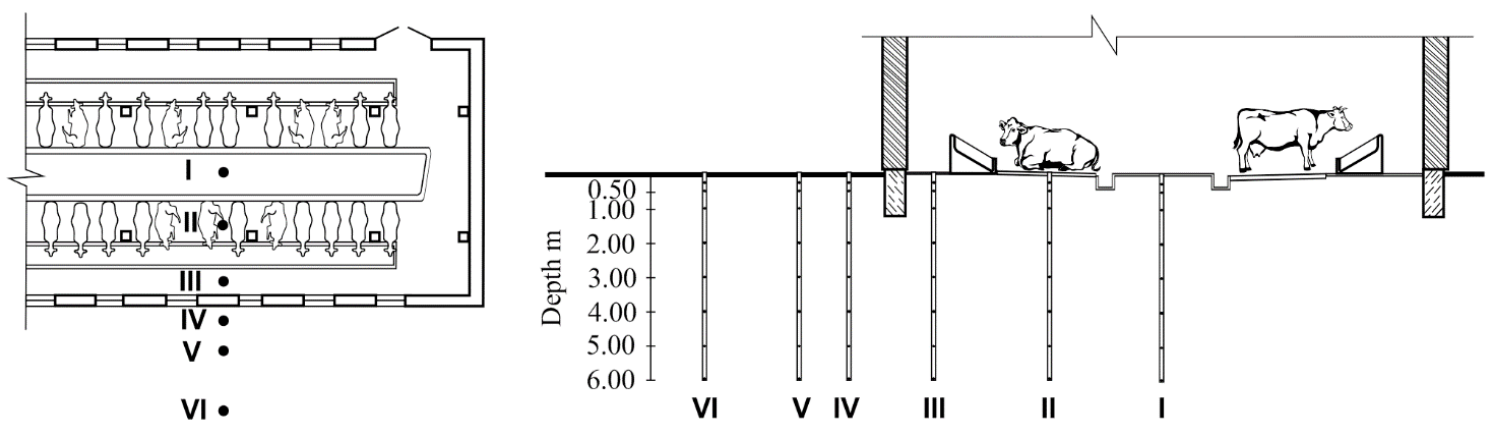

Figure 2. A part of the plan of cowshed building and arrangement of the measuring boreholes of the ground temperature of the cowshed internal base and external environment as well as temperature sensing depths in them (I-VI - borehole numbers)

Inside the cowshed 3 borings I, II, III with a diameter of $4 \mathrm{~cm}$ have been squeezed for the soil temperature investigations from the outside foundation up to the middle of the cowshed. Semiconductor transistor sensors have been let for the measurement of the temperature in every boring in vertical direction at a distance of $0,25 \mathrm{~m}, 0,5 \mathrm{~m}, 1,0 \mathrm{~m}, 2,0$ $\mathrm{m}, 3,0 \mathrm{~m}, 4,0 \mathrm{~m}, 5,0 \mathrm{~m}, 6,0 \mathrm{~m}$ from the land surface (Figure 2).

In the outdoor of the building at a distance of $0,6 \mathrm{~m}, 2,0$ and 5,0 $\mathrm{m}$ from the outdoor wall and IV, V, VI borings, mentioned sensors had been let into duplicate depth of the land surface. All borings up to the land surface were filled up with a mix of sand and gravel (Figure 2).

\section{RESULTS AND DISCUSSION}

The daily average air temperature changes outdoors and in the cowshed are shown in Figure 3 . From the data presented, we can see that the average temperature in the cowshed was by $1.1^{\circ} \mathrm{C}-8.5^{\circ} \mathrm{C}$ higher than the outdoor temperature. During this study period, the variation in cowshed air temperature compared to outdoor air temperature was observed. During the observed period, the lowest daily average outdoor air temperature was $-17.6^{\circ} \mathrm{C}$ and in the cowshed $-3.3^{\circ} \mathrm{C}$. Relative humidity varied during the study as outdoor air and cowshed air temperatures changed. The average daily air temperature in the cowshed ranged from $-3.3{ }^{\circ} \mathrm{C}$ to $11.1{ }^{\circ} \mathrm{C}$; average relative humidity between $67.4 \%$ and $95.2 \%$. The average daily air temperature varied from $-17.6{ }^{\circ} \mathrm{C}$ to $7.8{ }^{\circ} \mathrm{C}$; relative humidity varied from $75.4 \%$ to $98.1 \%$, respectively. It was found that temperature changes in the cowshed directly influence the change in relative humidity.

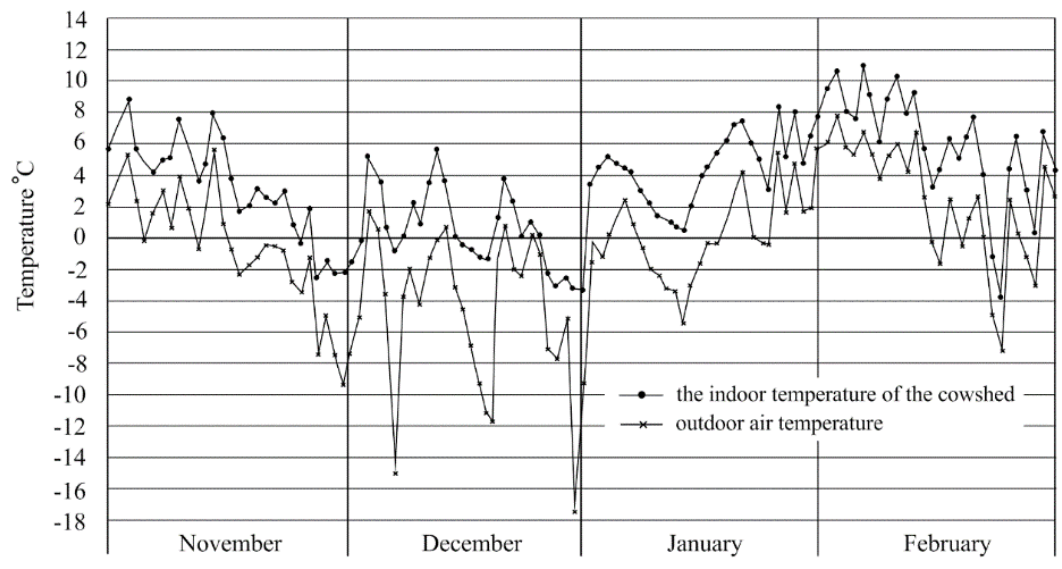

Figure 3. Changes in average daily air temperatures outdoors and in the cowshed

When a cow is lying down, there is a consistent warming process on the floor, which is colder than the cow's body. The animal's body conducts heat to the floor at a temperature below that of the cow. Depending on the thermal properties of the materials used for the bearing area, the cow accumulates part of the heat over a longer time, the difference between cow body surface temperature and floor narrowing, thus gradually stabilizing and stabilizing the process. When a cow rises, there is a consistent drop in temperature on the floor - the floor cools.

Below we look at the temperature changes in the floor and subsoil. Changes in the floor temperature during the coldest period were investigated (Figure 4). The average daily temperature on the floor during the coldest days was $18.2^{\circ} \mathrm{C}$ and $16.2^{\circ} \mathrm{C}$ below the floor. On the coldest day, the average temperature on the floor surface was $2{ }^{\circ} \mathrm{C}$ higher than on the subsoil. This difference in average temperature between the surface of the floor and beneath was caused by the heat transmitted from the cow lying on the floor to the floor. 
According to the soil temperature measurements in the animal bed place lodging (II borehole) it was determined, that in winter period soil temperatures from the floor surface in various depths $(h=0,0 \div 6,0)$ lower from $16,2{ }^{\circ} \mathbf{C}$ to 12,3 ${ }^{\circ} \mathbf{C}$. Soil temperatures in the VI borehole of the building zone showed, that soil temperatures from the land surface in different depths $(h=0,0 \div 6,0)$ increase average from $-4,7$ to $10,3{ }^{\circ} \mathbf{C}$. Such temperature distribution is influenced mostly by the climate. The sharper range in time of the soil temperatures is noticeable in $3 \mathrm{~m}$ depth when the depth is lower the temperature ranges only between $1-2{ }^{\circ} \mathbf{C}$.

As far as one can see from the II borehole, the maximum range of the temperature shows on the floor surface. The range of the temperature of the soil (investigated in November-February) on the whole is not significant. Such temperature repartition is determined by a steady source of heat energy - the temperature of the animal body. Big animals about $50 \%$ of their time, rest and the part of their body heats the floor surface (Mader et, al., 2006).

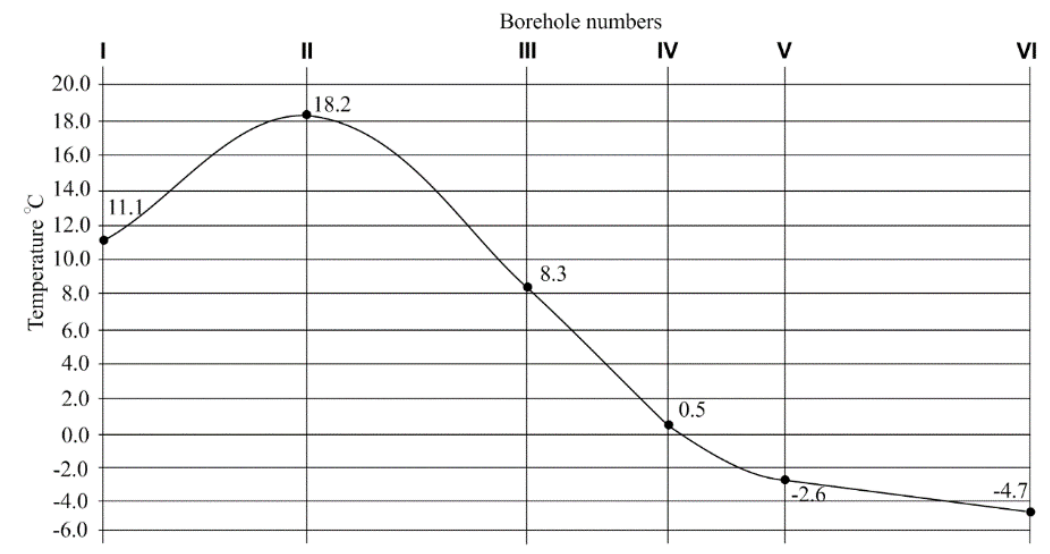

Figure 4. The average temperature on the surface: I - in the middle of the cow keeping room; II - in the cow standing place; III - inside the building near outside walls; IV-VI - outside the building

\section{CONCLUSIONS}

Measurements of the temperature of the cowshed floor and the surrounding ground showed that the ground temperature field is in a constant dynamic state. There is a heat exchange between the outside of the building and the ground beneath the building and the floor above them.

The temperature condition of the soil at the base of the cow is greatly influenced by the heat transmitted from the cow lying down.

In order to protect livestock from the adverse effects of low temperatures, it is appropriate to reduce the critical ambient temperature in the cowshed by controlling the heat exchange through the bearing area floor.

\section{REFERENCES}

1. Bagath M., Krishnan G., Devaraj C., Rashamol V. P., Sejian V. 2019. The impact of heat stress on the immune system in dairy cattle. Research in Veterinary Science, Vol. 126, pp. 94-102. https://doi.org/10.1016/j.rvsc.2019.08.011

2. DeShazer J.A., LeRoy H.G., Hongwei X. 2009. Chapter 1: Basic Principles of the Thermal Environment and Livestock Energetics. Agricultural and Biosystems Engineering Publications. Iowa State University, pp. 234. https://doi.org/10.13031/2013.28294

3. Gaughan J.B., Mader T.L., Holt S.M., Lisle A. 2008. A new heat load index for feedlot cattle. Journal of Animal Science, Volume 86, pp.226-234. https://doi.org/10.2527/jas.2007-0305

4. Hautala M., Ahokas, J., Ruunaniemi, J. 2001. Heat Transfer from Cow to Floor: Theory and Experiment. In International Conference of Agricultural Machinery, Building and Energy Engineering, pp.64-69.

5. Kavolèlis B., Bleizgys R. 2006. Optimum temperature and humidity regime of uninsulated cowshed. Journal of Environmental Engineering and Landscape Management, Vol. 14(2), pp. 89-94. https://doi.org/10.3846/16486897.2006.9636884

6. Polsky L., von Keyserlingk M. A.G. 2017. Effects of heat stress on dairy cattle welfare. Dairy Science, Vol. 100, pp.8645-8657. https://doi.org/10.3168/jds.2017-12651

7. Mader T.L., Davis M.S., Brown-Brandl T. 2006. Environmental factors influencing heat stress in feedlot cattle. Journal of Animal Science, Vol. 84, pp.712-719. https://doi.org/10.2527/2006.843712x

8. Nilsson C. 1988. Floors in Animal Houses: Report No. 61 Swedish University of Agricultural Sciences. Department of Farm Buildings. Lund (Sweden).

9. Sallvik K. G.1998. Environment for Animals. CIGR Handbook of Agricultural Engineering. Animal Production, Vol. II. Publisher by: American Society of Agricultural Engineers.

10.Sjostrom L. S., Heins B. J., Endres M. I., Moon R. D., Sorge U. S. 2019. Effects of winter housing system on hygiene, udder health, frostbite, and rumination of dairy cows. Journal of Dairy Science, Vol. 102, Iss. 11, pp. 10606-10615 https://doi.org/10.3168/jds.2018-15759

11.Turnpenny J.R., Wathes C.M., Clark J.A., McArthur A.J. 2006. Thermal balance of livestock: 2. Applications of a parsimonious model. Agricultural and Forest Meteorology, Vol. 101, Iss. 1, pp. 29-52. https://doi.org/10.1016/S0168-1923(99)00159-8 